\title{
Ocular Foreign Bodies: Evolution of Professional Roles and Public Costs in Quebec
}

\author{
Benoît Tousignant, \\ OD, MSc, MPH, FAAO \\ École d'optométrie, \\ Université de Montréal, \\ School of Public Health, \\ Université de Montréal \\ Drissa Moriba Coulibaly, \\ BOptom, MSc \\ Institut d'ophtalmologie \\ tropicale d'Afrique (IOTA)
}

Julie Brûlé, OD, MSc, FAAO

École d'optométrie, Université de Montréal

\section{Jacques Gresset,} OD, PhD, FAAO École d'optométrie, Université de Montréal

\section{Abstract}

In 2003, Quebec optometrists were legally permitted to extract superficial ocular foreign bodies, with part of this service covered by universal health insurance. This study analyses the changing roles for professionals managing this condition (optometrists, ophthalmologists, emergency physicians and family physicians) and the related public healthcare costs.

\section{METHODS}

Data from the provincial health insurance were combined with demographic and annual healthcare workforce statistics. Across professions and sociosanitary regions, variations in annual rates of conditions treated were calculated, as well as variations in public healthcare costs. Linear regression slopes of these variations were used as indicators of linear trends.

\section{RESULTS}

Between 2010 and 2016, the proportion of cases managed by optometrists significantly increased from $32 \%$ to $44 \%$ ( $\mathrm{p}<0.007)$. For family physicians, the proportion of cases managed significantly decreased from $49 \%$ to $33 \%$ $(\mathrm{p}<0.0001)$. The increase in optometrist-managed cases is visible in almost all sociosanitary regions, reaching $+19 \%$. Healthcare costs significantly increased for optometrists $(p<0.008)$ and ophthalmologists $(p<0.004)$ and significantly decreased for family physicians $(\mathrm{p}<0.001)$. In 2016 , optometrists managed $44 \%$ of cases, representing $13 \%$ of related healthcare costs.

\section{CONCLUSION}

In Quebec, optometrists now manage the largest proportion of superficial ocular foreign bodies. This is countered by an apparent decrease in the proportion of cases managed by family physicians.

\section{KEYWORDS}

eye foreign bodies; optometry; ophthalmology; emergency treatment; health services accessibility; health expenditures

\section{INTRODUCTION}

Superficial ocular foreign bodies (SOFBs) are small solid bodies that project into an eye, injuring the anterior layers of the cornea or contributing to conjunctivitis. SOFBs most often affect males and arise from work-related injuries. ${ }^{1-3}$ Although SOFBs carry lower risks of morbidity than intraocular foreign bodies, they carry a risk of visual disability and often lead to costs arising from workforce compensation. ${ }^{4-6}$

Management of SOFBs is a primary eye care procedure, which consists of a trained professional locating and removing the SOFB under local topical anaesthesia with the appropriate ophthalmic instruments, usually with a slit lamp? 
Until 2003, in the Canadian province of Quebec, the cost of SOFB removal was covered under the universal public healthcare program (Régie de l'assurance-maladie du Québec, RAMQ) for ophthalmologists, emergency physicians and family physicians.

Ophthalmologists are specialized medical doctors who provide medical and surgical eye care, ${ }^{8}$ which includes the management of SOFBs. In 2016, there were 400 ophthalmologists in Quebec (1:20,815 inhabitants). ${ }^{9}$ While their services are in constantly increasing demand, their numbers are growing more slowly than the aging population which is in need of ophthalmic services. ${ }^{10,11}$ Emergency physicians are specialized medical doctors who provide care in hospital emergency rooms, including the management of SOFBs, with referral to ophthalmology as needed. There are 200 of these specialists in Quebec (1:41,631 inhabitants). ${ }^{9}$ In 2016, there were 10,779 family physicians in Quebec (1:772 inhabitants) ${ }^{9}$ and they accounted for more than $85 \%$ of the doctors working in emergency rooms (Fédération des médecins omnipraticiens du Québec [FMOQ], personal communication, 2017). Thus, family physicians also manage SOFBs. Delays in hospital emergency rooms can reach up to 48 hours. $^{12}$

In Quebec, optometrists are the primary eye care providers; they are trained to identify and therapeutically treat certain types of ocular pathologies by topical or oral medications. ${ }^{13}$ The majority of optometrists work in private practice, but can bill the RAMQ for services delivered to specific groups (children, elderly) or across all age groups in certain instances (ocular emergencies, diabetes care, social assistance). With 1,499 optometrists (1:5,554 inhabitants) ${ }^{14}$ covering all sociosanitary regions of the province, they offer access to eye care for the population. ${ }^{14,15}$ In 2003 , following a widening of their scope of practice, optometrists were legally permitted to manage SOFBs that are superficial and not threatening to the central visual axis. ${ }^{13}$ The RAMQ covers the diagnostic portion (examination) of the related professional fees, and the therapeutic portion (extraction) is paid by the patient or their private complementary health insurance.

To date, no study has assessed the impact of the participation of optometrists in SOFB management in Quebec since their scope of practice was expanded. The objective of this study was to analyse the changes and distribution of SOFB management by the various professionals involved, as well as the changes in the related RAMQ costs.

\section{MATERIAL AND METHODS}

Data regarding SOFB management (number of procedures, number of patients, number of dispensing professionals and costs) by optometrists, ophthalmologists, emergency physicians and family physicians were obtained from RAMQ. Between 2003 and 2009, RAMQ data on optometrists managing SOFB were not available, as coding for SOFB was performed with a non-specific ocular emergency code. In 2009, a specific subcode for optometrists was introduced for SOFBs. Therefore, the study period covers 2010 - 2016. Relevant procedural and diagnostic codes for all professions were obtained after consulting RAMQ billing manuals, hospital RAMQ billing personnel, the College des médecins du Québec (provincial medical regulatory board) and the Association des optométristes du Québec (Quebec Association of Optometrists) (Table 1).

Table 1 : Procedure and diagnostic codes related to superficial ocular foreign body management in Quebec, 2010-2016

\begin{tabular}{|l|c|c|}
\hline & Procedure codes & Diagnostic codes \\
\hline Family physicians & 07204,07154 & $9309,9300,9301$ \\
\hline Ophthalmologists & 07204,07159 & $9309,9300,9301$ \\
\hline Emergency physicians & 07159 & $9309,9300,9301$ \\
\hline Optometrists & 9019, with subcode A00.8* & N/A \\
\hline
\end{tabular}

* Subcode A00.8 not available between 2003 and 2009, as optometry coding for superficial ocular foreign bodies (SOFB) was performed with a non-specific ocular emergency code. In 2009, this specific subcode for optometrists was introduced for SOFBs.

These data were combined with the distribution of the four types of professionals according to sociosanitary regions (SSR), as well as with government demographic data from the Institut de la statistique du Quebec. ${ }^{16,17}$ 
Absolute proportions of these professions managing SOFBs across SSRs were determined for 2010 and 2016 , along with their respective variations. The relative rates of SOFB patients per 100,000 inhabitants (SOFB/100,000) were also determined for each profession. A "patient" was defined as a person who had at least one healthcare visit billed to the RAMQ per year of reference. Total RAMQ costs for SOFBs for every 100,000 inhabitants (SOFB $\$ / 100,000)$ were determined for each profession. A simple linear regression was used to analyse the variation of SOFB/100,000 and SOFB $\$ / 100,000$ as predicted by study years, for each of the professions. T-tests on regression slopes were used to assess the significance of linear trends over the study period.

Statistical analyses were performed using SPSS (IBM Corp. 2016. IBM SPSS Statistics for Windows, Version 24.0. Armonk, NY).

\section{RESULTS}

SOFB management by professionBetween 2010 and 2016, for the whole province and for all professions combined, the rate of SOFB/100,000 decreased, and this change was statistically significant. The proportion of SOFBs managed by optometrists increased from $32 \%$ to $44 \%$ (Figure 1). Table 2 shows the regression model $\left(\mathrm{r}^{2}=0.79, \mathrm{~F}[1,6]=\right.$ 19.3, $\mathrm{t}=4.4, \mathrm{p}=0.007)$; there was a significant increasing trend, with an annual increase of 6.9 SOFB/100,000.

Figure 1: Changes in the management of superficial ocular foreign bodies by Quebec professionals (2010 - 2016)
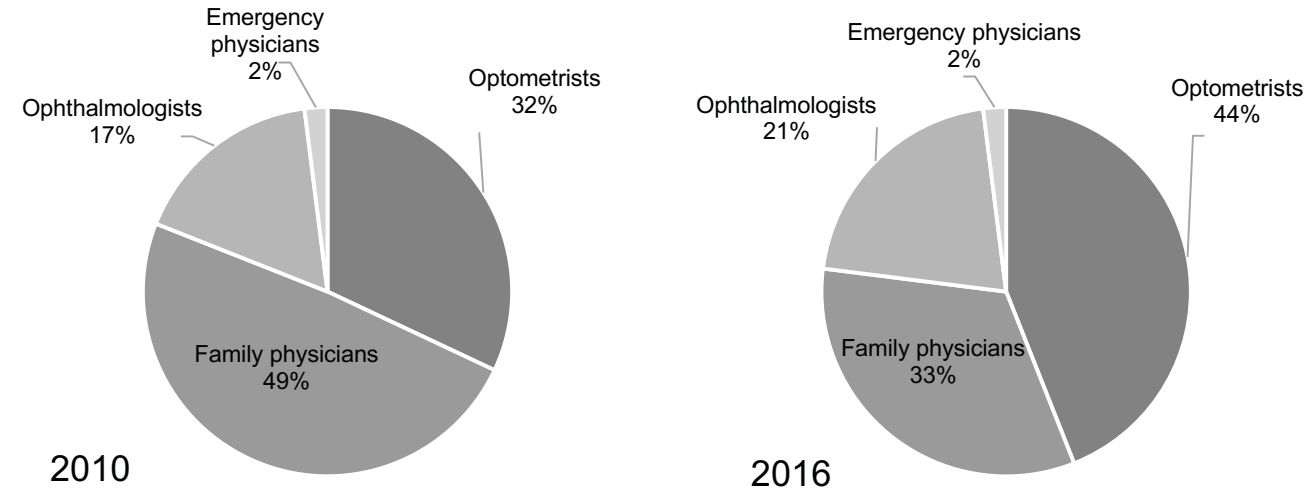

Table 2: Linear regression analysis of the yearly change in the rate of superficial ocular foreign bodies (per 100,000 individuals) for various health professions, Quebec, Canada, 2010-2016

\begin{tabular}{|l|c|c|c|c|c|c|c|}
\hline & $\mathbf{r}^{2}$ & $\mathbf{F}$ & $\mathbf{d f}$ & $\mathbf{t}$ & $\mathbf{p}^{*}$ & $\begin{array}{c}\beta \mathbf{0} \\
\text { (slope) }\end{array}$ & $\beta \mathbf{1}$ (intercept) \\
\hline All professions & 0.89 & 41.6 & 1,6 & -6.4 & 0.001 & -7.7 & 15943.0 \\
\hline Optometrists & 0.79 & 19.3 & 1,6 & 4.4 & 0.007 & 6.9 & -13703.7 \\
\hline Family physicians & 0.96 & 121.0 & 1,6 & -11.0 & $<0.001$ & -17.7 & 35752.95 \\
\hline Ophthalmologists & 0.57 & 6.6 & 1,6 & 2.6 & 0.05 & 3.1 & -6185.9 \\
\hline Emergency physicians & 0.02 & 0.1 & 1,6 & -0.28 & 0.8 & -0.04 & 79.9 \\
\hline
\end{tabular}

* values of $\mathrm{p}<0.05$ indicate a non-null regression slope and a statistically significant linear trend

For family physicians, the proportion of SOFBs managed decreased from $49 \%$ to 33\% (Figure 1). The regression model $\left(\mathrm{r}^{2}=0.96, \mathrm{~F}[1,6]=121.0, \mathrm{t}=-11.0, \mathrm{p}<0.001\right)$ shows a significant decreasing linear trend, with an annual decrease of 17.7 SOFB/100,000. For ophthalmologists, the proportion of SOFBs managed increased from $17 \%$ to $21 \%$ (Figure 1). The regression model $\left(\mathrm{r}^{2}=0.57, \mathrm{~F}[1,6]=6.6, \mathrm{t}=2.6, \mathrm{p}=0.05\right)$ shows a significant increasing trend, with an annual increase of $3.1 \mathrm{SOFB} / 100,000$. For emergency physicians, the proportion of SOFBs managed did not vary significantly, and remained steady at $2 \%$; the regression model failed to show any significant trend. 


\section{Changes in SOFB management in various SSRs}

During the study period, the increase in the proportion of SOFBs managed by optometrists is visible in all but one SSR (Table 3). However, this increase differed between urban, peri-urban and rural regions. In the city of Montreal, the proportion of SOFBs managed by optometrists increased by $12 \%$ (from $22 \%$ to $34 \%$ ). The increase among optometrists was $18 \%$ (from $41 \%$ to $59 \%$ ) in the peri-urban region of Montérégie, but only $3 \%$ (from $55 \%$ to $58 \%$ ) in the rural region of Laurentides. Conversely, the proportion of SOFBs managed by family physicians decreased in most SSRs, with variations mostly between $-6 \%$ and $-20 \%$ (Table 3 ).

Table 3: Geographic variations in the treatment of superficial ocular foreign bodies by Quebec professionals, 2010 - 2016.

\begin{tabular}{|c|c|c|c|c|c|}
\hline \multirow{2}{*}{$\begin{array}{l}\text { Sociosanitary } \\
\text { regions }\end{array}$} & \multirow{2}{*}{$\begin{array}{l}\text { Region } \\
\text { type }\end{array}$} & \multicolumn{4}{|c|}{$\begin{array}{l}\text { SOFBs treated by professionals in } 2016 \\
(\%, \text { variation from } 2010)\end{array}$} \\
\hline & & Optometrists & Family physicians & Ophthalmologists & Emergency physicians \\
\hline Montréal & Urban & $34 \%(+12 \%)$ & $20 \%(-15 \%)$ & $46 \%(+5 \%)$ & $2 \%$ (stable) \\
\hline Capitale-Nationale & Urban & $23 \%(+10 \%)$ & $54 \%(-8 \%)$ & $17 \%(-1 \%)$ & $6 \%(-1 \%)$ \\
\hline Laval & $\begin{array}{l}\text { Peri- } \\
\text { urban }\end{array}$ & $45 \%(+10 \%)$ & $19 \%(-18 \%)$ & $36 \%(+9 \%)$ & $8 \%(+3 \%)$ \\
\hline Montérégie & $\begin{array}{l}\text { Peri- } \\
\text { urban }\end{array}$ & $58 \%(+19 \%)$ & $21 \%(-17 \%)$ & $21 \%$ (stable) & $0 \%(0 \%)$ \\
\hline Bas-Saint-Laurent & Rural & $26 \%(+4 \%)$ & $49 \%(-20 \%)$ & $12 \%(+3 \%)$ & $0 \%(0 \%)$ \\
\hline $\begin{array}{l}\text { Saguenay-Lac-Saint- } \\
\text { Jean }\end{array}$ & Rural & $52 \%(+9 \%)$ & $36 \%(-14 \%)$ & $11 \%(+4 \%)$ & $0 \%(0 \%)$ \\
\hline Mauricie & Rural & $45 \%(+15 \%)$ & $43 \%(-14 \%)$ & $12 \%(-1 \%)$ & $0 \%(0 \%)$ \\
\hline Estrie & Rural & $36 \%(+13 \%)$ & $52 \%(-13 \%)$ & $12 \%(+1 \%)$ & $0 \%(-1 \%)$ \\
\hline Outaouais & Rural & $61 \%(13 \%)$ & $25 \%(-14 \%)$ & $14 \%(+1 \%)$ & $0 \%(0 \%)$ \\
\hline Abitibi-Témiscamingue & Rural & $49 \%(+1 \%)$ & $47 \%$ (stable) & $4 \%(-1 \%)$ & $0 \%(0 \%)$ \\
\hline Côte-Nord & Rural & $27 \%(+6 \%)$ & $57 \%(+3 \%)$ & $16 \%(-9 \%)$ & $0 \%(0 \%)$ \\
\hline $\begin{array}{l}\text { Gaspésie-îles-de-la- } \\
\text { Madeleine }\end{array}$ & Rural & $46 \%(+2 \%)$ & $45 \%(-6 \%)$ & $9 \%(+4 \%)$ & $0 \%(0 \%)$ \\
\hline Chaudière-Appalaches & Rural & $28 \%(+10 \%)$ & $52 \%(-16 \%)$ & $28 \%(+10 \%)$ & $0 \%(0 \%)$ \\
\hline Lanaudière & Rural & $46 \%(-4 \%)$ & $45 \%(+13 \%)$ & $9 \%(-9 \%)$ & $0 \%(-1 \%)$ \\
\hline Laurentides & Rural & $58 \%(+3 \%)$ & $16 \%(-17 \%)$ & $26 \%(+14 \%)$ & $0 \%(0 \%)$ \\
\hline TOTAL & & $44 \%(+12 \%)$ & $33 \%(-16 \%)$ & $21 \%(+4 \%)$ & $2 \%(0 \%)$ \\
\hline
\end{tabular}

SOFB: superficial ocular foreign body

\section{SOFB-related RAMQ costs}

Between 2010 and 2016, for the whole province and for all professions combined, the rate of SOFB $\$ / 100,000$ remained stable, with regression showing no significant linear trend (Table 4). In 2010, 11\% of RAMQ costs for SOFBs were attributable to optometrists, and this increased to $13 \%$ by 2016 (Figure 2 ). The regression model $\left(\mathrm{r}^{2}=0.79, \mathrm{~F}[1,6]=[18.2]\right), \mathrm{t}=4.3, \mathrm{p}$ $=0.008$ ) shows a significant increasing trend (Table 4). In 2010, family physicians generated 47\% of SOFB-related RAMQ costs, and this decreased to $37 \%$ by 2016 (Figure 2 ); the regression model $\left(\mathrm{r}^{2}=0.91, \mathrm{~F}[1,6]=51.1, \mathrm{t}=-7.2, \mathrm{p}<0.001\right)$ showed a significant decreasing trend (Table 4). In 2010, ophthalmologists generated $40 \%$ of SOFB-related RAMQ costs, and this increased to $47 \%$ by 2016 (Figure 2 ). The regression model $\left(r^{2}=0.83, F[1,6]=24.7, t=4.9, p=0.004\right)$ showed a significant increasing linear trend (Table 4). For emergency physicians, regression failed to show any significant trend. 
Table 4: Linear regression analysis of the yearly change in public healthcare costs of superficial ocular foreign bodies (per 100,000 inhabitants) for various health professions in Quebec, Canada 2010 - 2016

\begin{tabular}{|l|c|c|c|c|c|c|c|}
\hline & $\mathbf{r}^{2}$ & $\mathbf{F}$ & $\mathbf{d f}$ & $\mathbf{t}$ & $\mathbf{p}^{*}$ & $\begin{array}{c}\beta \mathbf{0} \\
\text { (slope) }\end{array}$ & $\begin{array}{c}\beta \mathbf{1} \\
\text { (intercept) }\end{array}$ \\
\hline All professions & 0.32 & 2.3 & 1,6 & 1.5 & 0.2 & 149.7 & -279026 \\
\hline Optometrists & 0.79 & 18.2 & 1,6 & 4.3 & 0.008 & -159300 & 80.5 \\
\hline Family physicians & 0.91 & 51.1 & 1,6 & -7.2 & 0.001 & 756323 & -371.1 \\
\hline Ophthalmologists & 0.83 & 24.7 & 1,6 & 4.9 & 0.004 & -753512 & 379.1 \\
\hline Emergency physicians & 0.74 & 14.5 & 1,6 & 3.8 & 0.01 & -122536 & 61.2 \\
\hline
\end{tabular}

* values of $\mathrm{p}<0.05$ indicate a non-null regression slope and a statistically significant linear trend

Figure 2: Changes in public healthcare costs related to the management of superficial ocular foreign bodies by Quebec professionals $(2010-2016)$
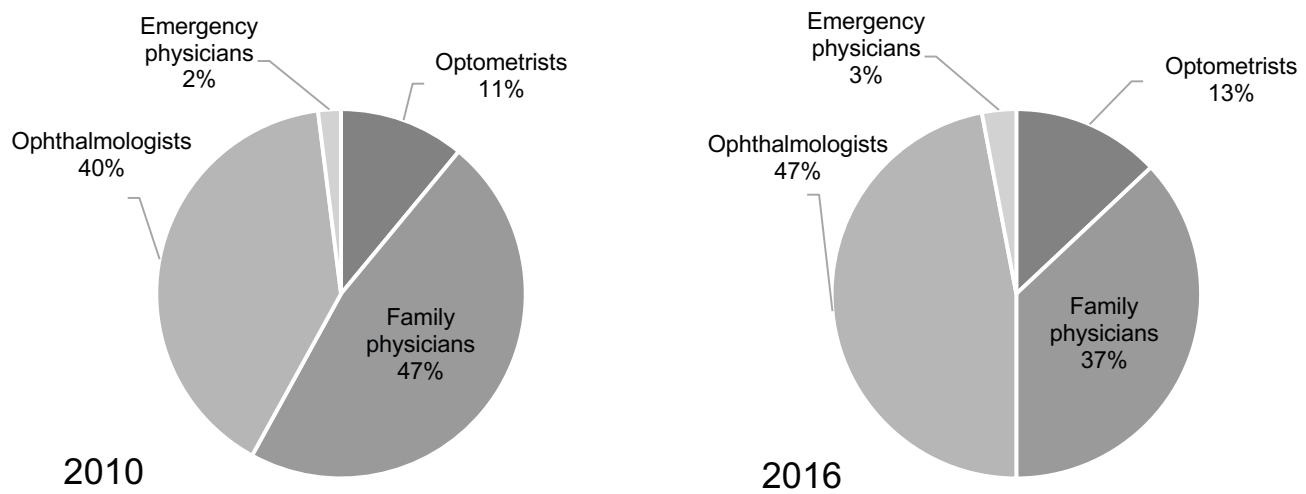

\section{DISCUSSION}

This study examined the changes in SOFB management in Quebec between 2010 and 2016, following the inclusion of optometrists among the various professionals who were legally permitted to perform SOFB extraction. During the study period, the overall number of SOFB managed by all professionals combined in Quebec decreased. While the causes for this finding are likely multifactorial, this decrease may be attributable to government efforts to improve workplace safety through health promotion and worker-protection policies. ${ }^{18}$

Unfortunately, no data are available for 2003 - 2009, when optometrists first started to manage SOFBs. However, it can be hypothesized that, during these initial years, there was a marked uptake of SOFB management by optometrists, considering that in 2010, $32 \%$ of SOFB removals were performed by optometrists (Table 2).

Between 2010 and 2016, at the provincial level, optometrists' SOFB/100,000 continued to increase slightly, following a significant linear trend, at a rate that was greater than the overall combined decrease in SOFB. The proportion of SOFB managed by optometrists increased to $44 \%$ in 2016, which made them the largest group of professionals who managed SOFBs (Figure 1). Conversely, during the same period, the SOFB/100,000 for family physicians significantly decreased; their proportion of managed SOFBs fell from 49\% (2010) to 33\% (2016). This observation is despite an $8 \%$ increase in the number of family physicians during this period. ${ }^{19}$ An exception is the Lanaudière SSR, which showed a 13\% increase in SOFB for family physicians, as well as decreases for optometry (-4\%) and ophthalmology (-9\%). This could be explained by the $16 \%$ increase in the number of family physicians, which is twice the provincial variation for the period. ${ }^{19}$ 
During the study period, SOFB/100,000 increased only slightly for ophthalmologists and remained stable for emergency physicians (Figure 1). Thus, we can presume that most of the increased share of SOFBs managed by optometrists was derived from the share previously managed by family physicians. This change may be explained by modified behaviors of the population when seeking eye care. Some patients may prefer optometrists to other professionals due to their greater accessibility, including reduced waiting times for appointments and ease of procuring care, compared to emergency rooms and ophthalmologists. ${ }^{20}$

Furthermore, given that most SOFB removals by family physicians are performed in hospital emergency rooms or walk-in emergency clinics (FMOQ, personal communication, 2017), this shift in SOFB management towards optometrists may contribute to reducing the congestion of emergency services available to the population.

Geographically, the increase in SOFBs managed by optometrists is notable across the province. In most SSRs, from 2006 to 2010 , this variation was between $+2 \%$ and $+19 \%$ (Table 2 ). The proportion of optometrists managing SOFBs is higher in rural and peri-urban areas than in urban areas. In 2016, in some rural areas, $60 \%$ of SOFBs were managed by optometrists, presumably where optometrists are more accessible. Conversely, in 2016, in urban SSRs, between $23 \%$ and $34 \%$ of SOFBs were managed by optometrists, second to ophthalmologists (Montreal) and family physicians (Quebec city). Some of the changes in the proportion of SOFBs managed by optometrists in rural areas are rather small (Gaspésie-Îles-de-la-Madeleine $+2 \%$, Laurentides $+3 \%$ ). However, considering that, in 2010 , optometry was already the leading profession for managing SOFBs in those SSRs (Gaspésie-îles-de-la-Madeleine 44\% and Laurentides 56\%), these areas can be considered to be "early adopters" of the management of SOFBs by optometrists, which had perhaps already reached a certain steady state between 2003 and 2009, before the study period.

Across professions, the cost of public health care coverage by the RAMQ for SOFBs did not vary significantly during the study period (Table 2). However, if we consider only family physicians, these costs significantly decreased, corresponding to their reduced share of SOFB management. For optometrists, these costs increased slightly (from 11\% to $13 \%$ of total RAMQ-related costs), following the increase in their share of SOFB management in the same period. RAMQ reimbursement fees for optometrists stayed stable during that period. ${ }^{21}$ For ophthalmologists, RAMQ costs for SOFBs increased from $40 \%$ to $47 \%$ of the total RAMQ costs for SOFBs. Since the SOFB/100,000 ratio for ophthalmologists increased only slightly, this increase in costs is more likely due to the increase in RAMQ reimbursement fees which occurred during that period..$^{22}$

Interestingly, in 2016, optometrists managed $44 \%$ of SOFBs, which represented only $13 \%$ of the related RAMQ costs. In contrast, ophthalmologists managed $21 \%$ of SOFBs, but $47 \%$ of the related RAMQ costs. One factor that may have contributed to this result is that, in 2016, average RAMQ costs per SOFB were lower for optometrists ( $\$ 13$ CAD) (data not shown) than for ophthalmologists (\$95 CAD) (data not shown). Furthermore, since RAMQ only reimburses optometrists for the diagnostic part of a SOFB visit, patients must pay for the therapeutic portion (SOFB removal) privately. In 2016, the Association des optométristes du Québec suggested fees of \$39 CAD - \$57 CAD for this procedure. ${ }^{23}$ Some private complementary insurance plans will cover these fees, and patients without this type of insurance may choose to pay out of pocket, perhaps favoring the quicker access to an optometrist. However, ultimately, when optometrists manage a SOFB in Quebec, a portion of the total costs are transferred out of the public system and to the patient or their private complementary insurance. This is not the case when the SOFB is managed by an ophthalmologist, a family physician or an emergency physician.

This study has several limitations, including potential errors from miscoding and billing errors to the RAMQ. For family and emergency physicians as well as for ophthalmologists, there are many different coding procedures for SOFB management, and coding may be managed by multiple billing agents, increasing the risk of errors. For optometrists, who have only one code and subcode for a SOFB, this risk is potentially decreased.

Another limitation is the definition used for a SOFB event (patient who had at least one health care visit billed to the RAMQ per year of reference), which may not account for the same individual having more than one SOFB in a given year. An alternative analysis could have been possible, using instead RAMQ data for the number of examinations in the population with a diagnostic code of SOFB. This would have included all cases, including those with multiple SOFBs during the same year. However, since many episodes of SOFBs have a potential for follow-up visits, the risk of overestimating the number of cases was worse than in the chosen analysis, regarding the inability to differentiate between initial and follow-up visits for the same SOFB episode. 
Lastly, there are certain circumstances where SOFBs may be managed without the specific procedure being billed to the RAMQ, which would exclude these cases from the current analysis. Examples include cases managed by nurse practitioners in remote areas or by ophthalmology of family medicine residents when no attending physician is available for procedure-based RAMQ billing, such as during certain night shifts. However, it is expected that the number of these instances is low compared to the total volume of cases included in the data shown here.

\section{CONCLUSION}

In Quebec, after their scope of practice was expanded by law, optometrists are now the professionals who manage the largest proportion of SOFBs throughout the province. The transfer of this burden seems to have been derived from the proportion of SOFBs that are managed by family physicians in emergency settings, which has decreased to a similar extent. This may contribute to reducing pressure and waiting times in emergency settings. The public healthcare (RAMQ) costs related to SOFBs is lower when optometrists manage SOFBs, but some of these costs are transferred out of the public system.

\section{ACKNOWLEDGEMENTS}

The authors acknowledge the Association des optométristes du Québec for funding the data-collection as well as Régie de l'assurance-maladie du Québec, the Collège des Médecins of Quebec, the Fédération des médecins omnipraticiens du Québec and the archives department of Montreal's Jewish General Hospital for their collaboration in gathering and contextualizing data for this study.

\section{DECLARATION OF INTEREST}

None

CORRESPONDING AUTHOR

Benoit Tousignant, benoit.tousignant@umontreal.ca

\section{REFERENCES}

1. Burrillon C. [Foreign bodies in the anterior segment]. J Fr Ophtalmol. 2001;24:751-757.

2. Islam SS, Doyle EJ, Velilla A, Martin CJ, Ducatman AM. Epidemiology of compensable work-related ocular injuries and illnesses: incidence and risk factors. J Occup Environ Med. 2000;42:575-581.

3. Ahmed F, House RJ, Feldman BH. Corneal Abrasions and Corneal Foreign Bodies. Prim Care. 2015;42:363-375.

4. Gonul S, Bozkurt B, Okudan S. Metallic corneal foreign bodies: an occupational health hazard. Arq Bras Oftalmol. 2014;77:411.

5. Gumus K, Karakucuk S, Mirza E. Corneal injury from a metallic foreign body: an occupational hazard. Eye Contact Lens. 2007;33:259260.

6. Aziz MA, Rahman MA. Corneal foreign body--an occupational hazard. Mymensingh Medical Journal : MMJ. 2004;13:174-176.

7. Newell SW. Management of corneal foreign bodies. Am Fam Physician. 1985;31:149-156.

8. Canadian Ophthalmological Society, 2019. http://www.cos-sco.ca/ vision-health-information/your-ophthalmologist/ Accessed: 25-022019

9. Collège des médecins du Québec, 2019. http://www.cmq.org/hub/ fr/statistiques.aspx Accessed: 2019-02-25

10. Resnikoff S, Felch W, Gauthier TM, Spivey B. The number of ophthalmologists in practice and training worldwide: a growing gap despite more than 200,000 practitioners. Br J Ophthalmol. 2012;96:783-787

11. Jeannin A, Mouriaux F, Mortemousque B. [Management of ophthalmologic emergencies in general emergency departments: A retrospective multicenter study]. J Fr Ophtalmol. 2016;39:589-595.

12. ESG Média [Index Santé], 2017. http://www.indexsante.ca/urgences/ Accessed: 2017-03-02
13. Gouvernement du Québec. Optometry Act. chapter O-7, s. 19.4, 2018. http://legisquebec.gouv.qc.ca/en/showdoc/cr/O-7,\%20r.\%2011.1. Accessed: 2019-02-25

14. Ordre des optométristes de Québec, 2017. https://www.ooq.org/ collaboration-interprofessionnelle/loptometriste-en-tant-queressource-de-premiere-ligne-en-sante Accessed: 20-03-2017

15. Bellan L. The geographic distribution of optometrists in Ontario. Can J Ophthalmol. 2015;50:92-93.

16. Institut de la Statistique du Québec. Perspectives démographiques du Québec et des régions, 2011-2061. 2014. http://www.stat.gouv. qc.ca/statistiques/population-demographie/perspectives/perspectives-2011-2061.pdf, Accessed 2019-02-25.

17. Institut de la statistique Quebec. Profils statistiques par région et MRC géographiques (Statistical profiles by regions). 2010-2016. http://www.stat.gouv.qc.ca/statistiques/profils/region_00/region_00.htm, Accessed 2019-02-25.

18. Gouvernement du Québec. Act respecting occupational health and safety. chapter S-2.1, 2017. http://legisquebec.gouv.qc.ca/en/ShowDoc/cs/S-2.1. Accessed: 2019-02-25

19. Collège des médecins du Québec, 2016. http://www.cmq.org/ publications-pdf/p-4-2016-06-09-fr-rapport-annuel-2015-2016.pdf Accessed: 2019-02-25

20. ESG Média [Index Santé], 2017. http://www.indexsante.ca/urgences/ Accessed: 2019-02-25

21. Régie de l'assurance maladie du Québec. Manuel des optométristes, no 2402016.

22. La Régie de l'assurance maladie du Québec. Manuel des médecins spécialistes Montréal: RAMQ; 2017.

23. Association des optométristes du Québec. Guide sommaire des tarifs (Annual fees guide). Montréal, Quebec: 2017. https://www. aoqnet.qc.ca/, Accessed 2019-02-25. 